\title{
Life threatening hypophosphataemia in a patient with Philadelphia chromosome-positive chronic myelogenous leukaemia in acute blastic crisis
}

\author{
P. Ra'anani, M. Lahav, M. Prokocimer ${ }^{1}$, L. Poles and E. Theodor \\ Department of Medicine 'E', 'Department of Hematology, Beilinson Medical Center, Petah Tiqva, \\ Sackler School of Medicine, Tel Aviv University, Israel
}

\begin{abstract}
Summary: Life-threatening hypophosphataemia developed in a 47 year old woman with blastic crisis of chronic myelogenous leukaemia. The patient's hospitalization was characterized by reciprocal relationship between her white cell count and the serum phosphorus levels. The patient did not demonstrate any of the usual causes of profound hypophosphataemia. The postulated mechanism of this patient's hypophosphataemia is uptake by the rapidly dividing leukaemic cells. To the best of our knowledge this is the first case in the English literature of hypophosphataemia associated with blast crisis of Philadelphia chromosome-positive chronic myelogenous leukaemia.
\end{abstract}

\section{Introduction}

Several conditions are known to induce moderate to severe hypophosphataemia. Although it is well established that rapid cell synthesis and turnover may be associated with high phosphorus consumption, hypophosphataemia is a relatively infrequent complication of neoplastic diseases and, if at all, is usually associated with parathyroid hormone-like peptide production. ${ }^{1}$ Hypophosphataemia associated with haematological malignancies has been reported infrequently. ${ }^{1-14}$

We report here a patient with Philadelphia chromosome-positive chronic myelogenous leukaemia $(\mathrm{CML})$ in acute blastic crisis who had episodes of profound symptomatic hypophosphataemia preceding the rise in number of peripheral blasts. The apparent cause for this patient's hypophosphataemia was uptake by the leukaemic blasts.

To the best of our knowledge this is the first case in the English literature of hypophosphataemia associated with blast crisis of Philadelphia chromosome-positive CML.

\section{Case report}

A 47 year old woman, suffering from Philadelphia chromosome-positive CML, was admitted to the

Correspondence: M. Lahav, M.D., Department of Medicine 'E', Beilinson Medical Center, Petah Tiqva 49100, Israel.

Accepted: 23 September 1991 hospital because of pain in both hip joints and fever. There was a history of non-insulin-dependent diabetes mellitus.

Physical examination revealed an ill and pale patient. Temperature was $38^{\circ} \mathrm{C}$, pulse 120 beats/ min and regular. There was generalized lymphadenopathy. A firm tender spleen and liver were palpable. Haemoglobin level was $8.7 \mathrm{~g} / \mathrm{dl}$, white cell count (WBC) was $80.5 \times 10^{9} / 1$ on admission and rose to $197.0 \times 10^{9} / 1$ within the next 3 days, with $30 \%$ blast forms. Platelets were $29 \times 10^{9} / 1$. A diagnosis of acute blast crisis, myelomonocytic type, based on cytochemical and immunological evaluation was established.

Serum sodium was $136 \mathrm{mmol} / \mathrm{l}$, potassium 4.2 $\mathrm{mmol} / \mathrm{l}$, uric acid $375 \mu \mathrm{mol} / \mathrm{l}$, calcium $2.2 \mathrm{mmol} / \mathrm{l}$ and phosphorus $1.19 \mathrm{mmol} / \mathrm{l}$. Serum urea nitrogen and the creatinine which were $6.86 \mathrm{mmol} / \mathrm{l}$ and $202 \mu \mathrm{mol} / 1$, respectively, decreased to normal values after hydration. Blood glucose levels were within normal limits. The remainder of the laboratory tests were within normal limits. The patient was treated with daunorubicin $30 \mathrm{mg} / \mathrm{m}^{2}$ and increase of the hydroxyurea dosage to $3.0 \mathrm{~g}$ daily.

During the following weeks a consistent relationship between the WBC and the serum phosphorus concentrations was noted. There were 5 cycles of hypophosphataemia. Each cycle was characterized by a precipitous fall in the phosphorus concentration to extremely low levels, preceding a rapid rise in the WBC to extremely high values. After each increase in WBC, daunorubicin was administered with subsequent decrease in WBC and increase in 
phosphorus levels (Figure 1).

The extreme hypophosphataemia in the patient was accompanied by symptomatic heart failure and neurological symptoms including tachycardia, dyspnoea, peripheral oedema and perimental paresthesias.

Although an extensive search for an infectious agent failed to reveal a pathogen, the patient was treated with broad spectrum antibiotics including amphotericin B. Nevertheless, despite all efforts, the patient died on her 76th hospitalization day. Permission for autopsy was not granted.

\section{Special studies}

In evaluation of the aetiology of the patient's hypophosphataemia the following studies were performed. Parathyroid hormone values were measured twice at between 50 and $60 \mathrm{pmol} / 1$ (normal values $30-85 \mathrm{pmol} / 1$, midmolecule parathyroid hormone RIA). 1,25-dihydroxyvitamin D (radioreceptor assay) was 37.1 picograms $/ \mathrm{ml}$ (normal values: $16-42 \mathrm{pg} / \mathrm{ml}$ ). Urinary cAMP measured $3 \mathrm{mmol} / 1$ (normal values $2-4 \mathrm{mmol} / \mathrm{ml}$ ) and tubular reabsorption of phosphate (TRP) ranged from $98.7-98.8 \%$ during periods of profound hypophosphataemia (normal values $>85 \%$ ).

\section{Discussion}

Several potential causes that could contribute to our patient's hypophosphataemia were ruled out, namely nutritional causes, antacids ingestion, renal phosphorus loss, sepsis or diabetic ketoacidosis. $^{3,15-17}$

\section{WBC Phosphorus}

$10^{9} / \mathrm{L} \mathrm{mmol} / \mathrm{L}$

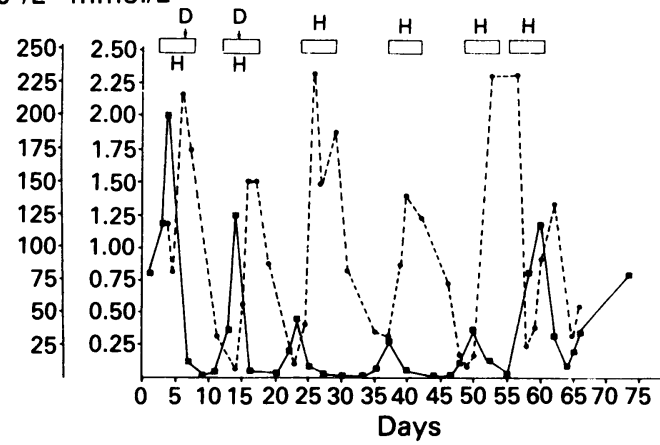

Figure 1 Phosphorus levels and white cell counts changes during patient's hospitalization. The solid line represents the whilte cell counts and the broken line the phosphorus levels. $\mathrm{H}$ represents increase in the hydroxyurea dosage. $\mathrm{D}$ represents daunorubicin administration.
Acute leukaemia by itself is capable of altering the normal physiological regulation of most electrolytes. ${ }^{1,2,4,5,11-14}$ Table I lists the reported cases of leukaemia-associated hypophosphataemia.

In this patient there was no evidence that the cause of hypophosphataemia was hyperparathyroidism, osteoblast stimulating factor production, interference with 25-hydroxylation of vitamin $D_{3}$, renal tubular leak due to lysosymuria or oncogeneous osteomalacia. . $3-5,15,18-24^{-1}$

Severe hypophosphataemia has occasionally been reported in coincidence with blast cell proliferation in haematological patients (Table I). ${ }^{1,3,6-10}$ Hypophosphataemia in those cases was usually attributed to the excessive uptake of phosphorus by the proliferating cells. In these patients, as in our patient, TRP, if measured, was very high during periods of blastic replication and decreased after the initiation of chemotherapy with cell lysis and the development of hyperphosphataemia.

The data in the present case suggest that the decrease in phosphate levels was due to changes in its transcellular distribution. The rapid replication of the malignant cells might have increased the demand for phosphate by its uptake by the rapidly dividing cells, resulting in profound hypophosphataemia. The high TRP values during periods of severe hypophosphataemia and the fact that the rapid fall in serum phosphate concentrations ha begun several days before the steep rise in peripheral blast counts, strongly suggest transcellula shift with intracellular trapping of phosphorus in the replicating cells, as the possible mechanisms for hypophosphataemia in this patient. A postulated mechanism for this hypothesis is based on the fact that blast cells derived from the myeloid series fail to show inhibition of glycolysis by oxygen. ${ }^{3}$ Therefore, in the presence of ambient concentrations of oxygen, myeloblasts show increased rates of aerobic glycolysis as compared to normal myeloid tissue. The enhanced rate of aerobic glycolysis that the leukemic myeloblasts undergo causes redistribution of large amounts of extracellular phosphate into the intracellular environment to provide phosphate for glycolytic intermediates. ${ }^{17}$ This causes a fall in phosphate levels in the blood and in nonmyeloid tissues, with hypophosphataemia ensuing despite total body phosphorus in the normal range.

In Figure 1, one can see a lag of 4-5 days between the beginning of the decline in serum phosphorus levels and that of the steep rise in the number of blasts in peripheral blood. This can be explained by the fact that there is a transit time of 2-5 days between blast cells genesis in bone marrow and their appearance in peripheral blood. During this period, the leukaemic blasts in the bone marrow use phosphate for their enhanced metabolic activity, including the aerobic glycolysis. This might lead to a fall in serum phosphate levels before 
ङัँ

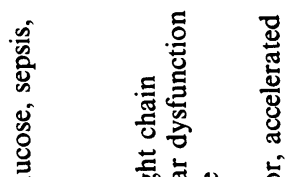

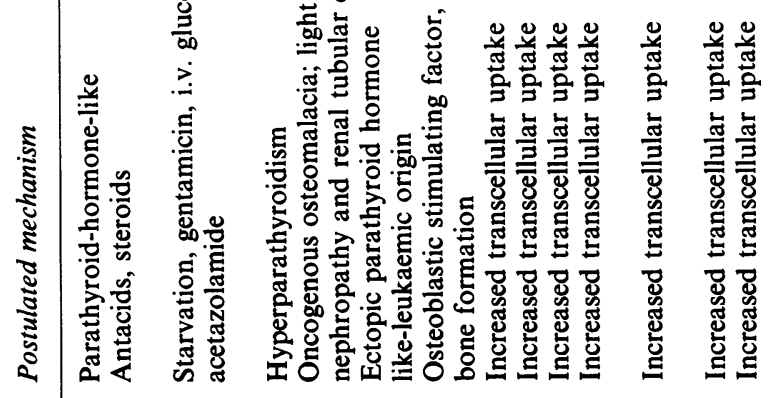

苋

苋

突

ธิ ธิ

总 零

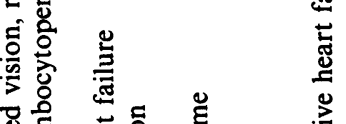

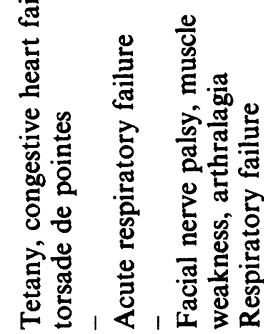

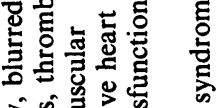

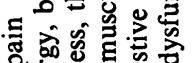

离

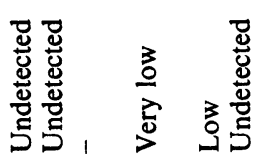

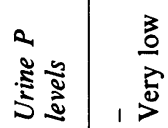

單哭

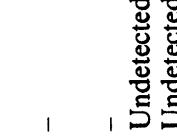

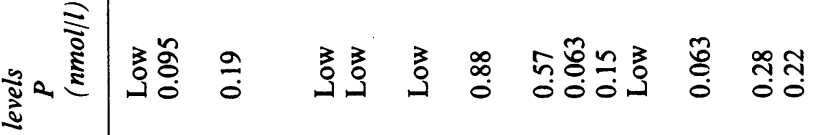

ई

ฟั้

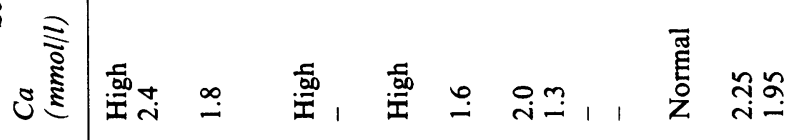

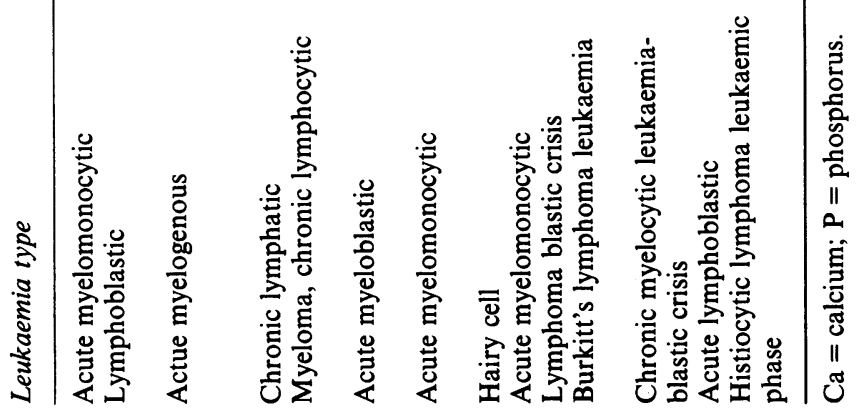


the overt appearance of leukaemic blasts in peripheral blood.

There is a possibility therefore, that in patients with blastic crisis, hypophosphataemia should be considered as an index of enhanced disease activity even before there is evidence for it in the peripheral blood smear. Serum phosphate concentration

\section{References}

1. Matzner, Y., Prokocimer, M., Polliack, A., Rubinger, D. \& Popovitzer, M.M. Hypophosphatemia in a patient with lymphoma in leukemic phase. Arch Intern Med 1981, 141: 805-806.

2. Aderka, D., Shoenfeld, Y., Santo, M. et al. Life threatening hypophosphatemia in a patient with acute myelogenous leukemia. Acta Haemat 1980, 64: 117-119.

3. Zamkoff, K.W. \& Kirschner, J., Marked hypophosphatemia associated with acute myelomonocytic leukemia. Indirect evidence of phosphorus uptake of leukemic cells. Arch Intern Med 1980, 140: 1523-1525.

4. O'Reagan, S., Carson, S., Chesney, R.W. \& Drummond, K.M. Electrolyte and acid base disturbances in the management of leukemia. Blood 1977, 49: 345-353.

5. Schenkein, D.P., O'Neil, W.C., Shapiro, J. \& Miller, K.B. Accelerated bone formation causing profound hypocalcemia in acute leukemia. Ann Intern Med 1986, 105: 375-378.

6. Hirokawa, M., Fukuda, M., Nimura, T. et al. Severe hypophosphatemia in a patient with chronic myeloid leukemia in blast crisis. Rinsho-Ketsueki 1986, 28: 228-232.

7. Le-Prise, P.Y., Oudry, B. \& Richier, J.L. Trouble du metabolisme des phosphates au cours d'une leucemie aigue lymphoblastique. Nouv Presse Med 1974, 3: 896.

8. Bar-Khayim, Y., Haran, N., Gurwicz, S., Berebi, A. \& Popovitzer, M.M. Transient hypophosphatemia associated with hairy cell leukemia. Harefuah 1990, 118: 83-85.

9. Perek, J., Mittelman, M., Gafner, U. \& Djaldetti, M. Hypophosphatemia accompanying blastic crisis in a patient with malignant lymphoma. J Cancer Res Clin Oncol 1984, 108: $351-353$.

10. Wollner, A., Shalit, M. \& Brezis, M. Tumor genesis syndrome. Miner Electrolyte Metab 1986, 12: 173-175.

11. Clarkson, O., Blondin, J. \& Cryer, P.E. Phosphate depletion and glucocorticoid induced hyperphosphatemia in lymphoblastic leukemia. Metabolism 1973, 22: 611-616.

12. Klaushofer, K., Koller, K., Baumgartner, G. et al. Hyperparathyroidism and chronic lymphocytic leukemia. Acta Med Austriaca 1981, 8: 7-14.

13. Rao, D.S., Parfitt, A.M., Villanueva, A.R., Dorman, P.J. \& Kleerekoper, M. Hypophosphatemic osteomalacia and adult Fanconi syndrome due to light chain nephropathy. Another form of oncogenous osteomalacia. Am J Med 1987, 82: 333-338. should therefore be closely monitored in such patients and bone marrow aspiration and treatment should be considered in a leukaemic patient presenting with severe hypophosphataemia, even before an increase in white cell count in peripheral blood is noticed.
14. Zidar, B.L., Shadduck, R.K., Winkelstein, A., Zeigler, Z. \& Hawker, C.D. Acute myeloblastic leukemia and hypercalcemia. A case of probable ectopic parathyroid hormone production. N Engl J Med 1976, 295: 692-694.

15. Knochel, $\mathbf{P}$. The pathophysiology and clinical characteristics of severe hypophosphatemia. Arch Intern Med 1977, 137: 203-220.

16. Riedler, G.F. \& Scheitlin, W.A. Hypophosphatemia in septicemia: higher incidence in gram negative than in gram positive infections. $\mathrm{Br}$ Med J 1969, 1: 753-756.

17. Mosrtellan, M.E. \& Tuttle, E.P. Effects of alkalosis on plasma concentration and urinary excretion of inorganic phosphate in man. $J$ Clin Invest 1984, 43: 138-149.

18. Broadus, A.E. Humoral hypercalcemia of cancer: identification of a novel PTH-like peptide. $N$ Engl J Med 1988, 319: 556-563.

19. Matsumoto, F.S. Clinical evaluation of calcium metabolism in adult T cell leukemia-lymphoma. Arch Intern Med 1988, 148: $921-925$.

20. Afzal Mir, M. \& Delamore, I.W. Metabolic disorders in acute myeloid leukemia. Br J Haematol 1978, 40: 79-92.

21. Wong, P., Hakamura, H. Endoh, N., Asai, T., Itoh, K. \& Yoshida, S. Decreased serum 1,25 dihydroxyvitamin $D_{3}$ levels in leukopenia. $\mathrm{Br} J$ Haematol 1986, 64: 844-847.

22. Fitzgerald, F. Clinical hypophosphatemia. Ann Rev Med 1978, 29: 177-189.

23. Kurokawa, K., Levine, B.J., Lee, D.N. \& Massry, S.G. Physiology of phosphorus metabolism and pathophysiology of hypophosphatemia and hyperphosphatemia. In: Ariess, A.I. and DeFrenzo, R.A. (eds) Fluids, Electrolytes and Acid Base Disturbances. New York, Churchill Livingstone, 1985, pp. 636-646.

24. Sudhaker Rao, D., Parfitt, A.M., Villanueva, A.R., Dorman, P.J. \& Kleerekoper, M. Hypophosphatemic osteomalacia and adult Fanconi syndrome due to light chain nephropathy. Am J Med 1987, 82: 333-337. 